\title{
Research on my country's Wetland Agricultural Ecological Planning and Landscape Design Based on American Experience
}

\author{
Lian Wang* \\ Jiangsu Construction Vocational and Technical College xuzhou Jiangsu 221116 ,China.
}

\begin{abstract}
This article summarizes and analyzes the American rural ecological wetland landscape agricultural design experience on the basis of summarizing the connotation of agricultural ecological planning landscape design, and draws on the successful experience of the United States, and proposes countermeasures based on the actual situation of agricultural wetland ecological planning landscape design in my country.

Keywords:American experience; Wetland agricultural ecological planning; Landscape design
\end{abstract}

\section{Introduction}

In recent years, some areas of our country have been in the transition stage from traditional agricultural landscape to modern agricultural landscape. The development of agricultural landscape has gone through three stages. First, traditional agricultural landscape, second, transition landscape from traditional agriculture to modern agriculture, and finally intensive. Modern agricultural landscape ${ }^{[1]}$. The development of modern agriculture has made possible the emergence of large areas of intensive farmland. The specialization and mechanization of agriculture have made the local landscape very monotonous. The increase in production comes at the expense of landscape diversity, reduction of local biological species and soil erosion. The increase. Combining my country's agricultural landscape planning and development, using the principles of landscape ecology to plan and design rural landscapes in my country is of great practical significance to promote the rational use of resources and the sustainable development of agriculture.

\section{American rural ecological landscape agriculture experience}

\subsection{Pay attention to the protection of landscape features}

Take Prairie Crossing as an example. When the precious local resources were gradually being swallowed up by industrialization, the environmentalists and other social forces bought the land. After careful design and planning, they rebuilt Prairie Crossing ${ }^{[2]}$. For the purpose of protecting the land, they reset the overall location of the village, landscape maintenance, traffic routes, etc., and finally built it into a clean, standardized and beautiful village. At the beginning of the planning, in order to avoid the destruction of the rural landscape, the designer adjusted the direction of vehicle entry and exit, and built a second railway station, which not only effectively protected the original landscape features, but also effectively used the rural customs to attract A large number of tourists came, achieving a win-win situation for both economic and environmental benefits.

\subsection{Adhere to the principle of ecological protection}

Copyright (C) 2020 Lian Wang

doi: 10.18282/l-e.v9i4.1681

This is an open-access article distributed under the terms of the Creative Commons Attribution Non-Commercial License (http://creativecommons.org/licenses/by-nc/4.0/), which permits unrestricted non-commercial use, distribution, and reproduction in any medium, provided the original work is properly cited.

\section{Summary}

As a comprehensive talent transportation college, vocational colleges not only need to pay attention to the cultural level of college students, but also need to improve and develop their English teaching at a certain level. While stimulating students' interest, higher vocational colleges should let students learn English happily and improve their English proficiency and gradually improve their mentality that students in higher vocational colleges think English learning is unnecessary. In the end, the college will gradually guide students to develop in a better and more comprehensive direction.

\section{Reference}

[1]Zhu Lingyun; 0 Comment on the construction of effective Classroom model of Professional English learning in higher vocational colleges in the new Normal period; Modernization of education; 018.

[2]liu; 08 Five Strategies for the Continuous Improvement of English teaching service quality in Higher vocational Colleges in China under the new situation; "Secondary School Teaching Reference"; 018. 
Prairie Crossing's redesign plan fully demonstrated the concept of environmental protection. On the one hand, the locals replaced lawns by planting native plants and wetland plants, which not only reduced chemical pollution, but also increased the rural atmosphere. On the other hand, the excavation of the artificial lake and the depression have achieved perfect integration, forming a very complete water storage system, and has a very strong water purification function, which realizes the unification of landscape characteristics and ecological protection. This is also the biggest highlight of Prairie Crossing's planning and construction process $^{[3,4]}$. This water circulation system continuously collects natural rainwater, and then transmits it to the grassland. After comprehensive filtering and retention, it is finally transmitted to an artificial lake, pond or wetland. The water becomes very clean. In order to achieve a good ecological protection effect, the local villagers also combined the growth habits of native plants and wetland plants to build a completely ecological "water courtyard" in their courtyard.

\subsection{Strengthen the development and utilization of renewable energy}

Prairie Crossing residents develop and use wind energy to maintain electricity for daily production and life. At the same time, they mainly use natural fertilizers when farming and fertilizing, and use biogas as fuel, which fully improves the secondary utilization rate of rural waste resources. Prairie Crossing's practice of advocating the use of clean energy is very worthy of our country's energy-consuming countries to learn and learn from. Increasing the development and utilization of renewable resources such as wind and solar energy in rural areas of our country is undoubtedly of very important practical significance.

\section{Enlightenment from the successful experience of foreign rural agricultural wetland ecological landscape}

\subsection{Build and improve the legal system}

The construction of rural ecological landscape is a long-term and systematic project. In order to ensure the smooth, orderly and reasonable progress of this project, it is necessary to construct a complete legal system to provide a strong guarantee for its development. At the same time, local governments must provide all-round support for development projects that meet the requirements, while projects that do not meet the requirements of laws and regulations must be suspended or punished in a timely manner.

\subsection{Adhere to the concept and principle of ecological protection}

Take the northwestern region of Liaoning as an example. Since this region is located in the transition zone between the east and the west of my country, it has a very significant ecological sensitivity. With the acceleration of my country's modernization process, over-exploitation and mining have brought a serious impact on the balance of the ecosystem in this area. According to authoritative data, the temperature in this area has been increasing year by year since the $1960 \mathrm{~s}^{[5]}$. Therefore, in the construction of rural ecological landscape, we must adhere to the concept and principles of ecological protection and adhere to the path of sustainable development. Taking the base pond system in the Pearl River Delta as an example, it is a special form of land use created by the local people using the natural conditions of abundant rainfall, low-lying terrain and frequent river flooding. In the heart of the Pearl River Delta river network zone, the concentrated distribution area of foundation ponds is $1120 \mathrm{~km} 2$, accounting for $1 / 10$ of the total area of the delta. The area of base and pond here accounts for $72.4 \%$ of the total land area, which is 3 times the area of cultivated land. The wetland landscape ecological project includes two parts: land base and fish pond. The base is the place where crops grow and the nutrient reservoir of mulberry, silkworm and fish in the entire ecosystem; while pond is the core of land use. The ratio of foundation to pond (ratio of land surface to water surface) is approximately 1:1.

\subsection{Inheriting traditional culture and improving human settlements}

Human beings have lived in groups since their birth. All tribes have their own unique historical origins. All countries and ethnic groups have their own historical and cultural characteristics that cannot be copied. Therefore, when constructing rural ecological landscapes in different regions, we must pay attention to localities. Protection and inheritance of characteristic culture ${ }^{[6]}$. For the construction of rural ecological landscape, the fundamental purpose is to promote the overall development of rural economy and improve the quality of life of rural residents. Therefore, in the development and construction of rural ecological landscape in our country, we must adhere to the people-oriented concept and principles and adopt the best Measures to maximize economic and ecological benefits, and promote the sustainable development of rural areas.

\subsection{Landscape model of multi-pond system in southern hilly area}

Various pits and ponds for water storage are widely distributed in the agricultural landscape in the hilly area of southern China, which is based on rice fields. The area varies from $10 \times 103$ to $10 \times 105$ square meters. The smaller is called pit, and the larger is called pit. Weitang is located in the foothills, fields and villages, and often becomes a part of the transition zone between land and larger inland water bodies. The typical proportion of ponds in this agricultural landscape is about $5 \mathrm{hm} 2$ (land). This is a field engineering system built by local farmers to adapt to the uneven and unstable rainfall of the subtropical monsoon climate and based on the hilly terrain and the needs of paddy field cultivation. This scattered arrangement of small ponds has an important ecological role in blocking surface runoff and sediment and filtering N P nutrients, and has become another model of rural landscape ecological construction in southern my country.

\section{Conclusion}

All in all, this article aims to find a balance point of wetland protection and utilization in the context of modern agricultural parks, so that agricultural parks can form a complete ecological cycle system. Protect wetland functions and wetland biodiversity, coordinate the ecology and production of modern agricultural parks, and enhance the ecological, recreational, cultural and educational functions of the wetland landscape of modern agricultural parks. 


\title{
Analysis on the Construction Framework and Realization Logic of Smart Laboratory System under the Environment of Internet of Things
}

\author{
Xin ying Wang* \\ Pingdingshan College, Henan 467002, China.
}

\begin{abstract}
The rapid growth of the Internet of Things has broken people's way of thinking and brought tremendous changes to people's lives. For key configurations, the Internet of Things is included in the central distribution component of cloud computing, transmission networks, and sensor acceptance techniques. The future Internet of Things is similar to the human body, with different induction and cognitive fields to complete functional tasks, and is a key component of work efficiency and the creation of intelligent control systems. The laboratory is a training ground for colleges and universities to cultivate creative and commercial talents, and has a special mission of cultivating skills and training talents. In recent years, the quality of laboratory knowledge has been greatly improved, but the management model can still meet the needs of teaching, laboratory and technology opening, scientific research, and the development of new and business talents. In the future, university laboratories should learn high-quality design ideas, use Internet of Things technology, Internet technology and ARM technology to build an effective intelligent management system to understand laboratory intelligence. Therefore, this article recommends a local Web-based laboratory construction program, aimed at improving the quality of test information services, while using Internet technology in the laboratory for RFID technology, wireless sensor network and ZigBee technology. Build a common speech and open platform. Based on the comprehensive collection and indepth analysis of test data, the platform provides applications and services for collaboration, sharing and application to fully meet the needs of different users (such as educators, students, and trial administrators), and focus on monitoring And manage university laboratories. In order for the country to better cultivate its engineering talents in the new era, this is important and historically significant.
\end{abstract}

Keywords: Internet of Things; Smart Laboratory System; Construction Framework

\section{Introduction}

The Internet of Things originated from the media industry and is the third innovation in the information industry. The Internet of Things refers to the use of sensing devices to connect anything in the network with information in accordance with agreed conditions. Objects exchange and communicate through information and media to identify professional knowledge, positioning, tracking, monitoring and other functions. The positioning of Internet products facing globalization is mainly concentrated in three areas:

Copyright (C) 2020 Xin ying,Wang

doi: $10.18282 / 1-$ e.v9i4.1682

This is an open-access article distributed under the terms of the Creative Commons Attribution Non-Commercial License (http://creativecommons.org/licenses/by-nc/4.0/), which permits unrestricted non-commercial use, distribution, and reproduction in any medium, provided the original work is properly cited.

\section{References}

[1]Biqing H, Feng P, Zhongyuan H . Planning Overall Landscapes,Building a Garden City:on the Revision of Guangzhou Urban Green Space System Planning[J]. Journal of Landscape Research, 2013(Z3).

[2]Zhang Xinwen, Shandong Agricultural University, Taian (China). RESEARCH ON ECOLOGICAL PLANNING METHOD

OF NORTH CHINA COASTAL WETLAND__ Taking Jincang National Wetland Park Master Plan in Laizhou Bay of Shandong Province as an Example[J]. Journal of Shandong Agricultural University, 2013.

[3]Zhen-Xing L I, Bi-Jun H, Shi-Lei F U , et al. Landscape Ecological Planning and Design of Urban Wetland Leisure Hotel[J]. heilongjiang agricultural sciences, 2016.

[4]Alves, Michelle, Ferreira, Joaquim Pedro, Torres, Inês. Habitat Use and Selection of the Marsh Harrier Circus aeruginosus in an Agricultural-Wetland Mosaic[J]. Ardeola Revista Iberica De Ornitologia, 2014, 61(2):351-366.

[5]Santelmann, Mary. Modeling Effects of Alternative Landscape Design and Management on Water Quality and Biodiversity in Midwest Agricultural Watersheds[J]. 2015.

[6]Barau A S , Qureshi S . Using agent-based modelling and landscape metrics to assess landscape fragmentation in Iskandar Malaysia[J]. Ecological Processes, 2015, 4(1):8. 